\title{
Northern Hemispheric Trends of Pressure Indices and Atmospheric Circulation Patterns in Observations, Reconstructions, and Coupled GCM Simulations
}

\author{
C. C. Raible, T. F. Stocker, M. Yoshimori, M. Renold, and U. Beyerle \\ Climate and Environmental Physics, Physics Institute, University of Bern, Bern, Switzerland \\ C. CASTY AND J. Luterbacher \\ Institute of Geography, University of Bern, Bern, Switzerland
}

(Manuscript received 5 February 2004, in final form 8 December 2004)

\begin{abstract}
The decadal trend behavior of the Northern Hemisphere atmospheric circulation is investigated utilizing long-term simulations with different state-of-the-art coupled general circulation models (GCMs) for present-day climate conditions (1990), reconstructions of the past $500 \mathrm{yr}$, and observations. The multimodel simulations show that strong positive winter North Atlantic Oscillation (NAO) trends are connected with the underlying sea surface temperature (SST) and exhibit an SST tripole trend pattern and a northward shift of the storm-track tail. Strong negative winter trends of the Aleutian low are associated with SST changes in the El Niño-Southern Oscillation (ENSO) region and a westward shift of the storm track in the North Pacific. The observed simultaneous appearance of strong positive NAO and negative Aleutian low trends is very unlikely to occur by chance in the unforced simulations and reconstructions. The positive winter NAO trend of the last $50 \mathrm{yr}$ is not statistically different from the level of internal atmosphere-ocean variability. The unforced simulations also show a strong link between positive SST trends in the ENSO region and negative Aleutian low trends. With much larger observed SST trends in the ENSO region, this suggests that the observed negative Aleutian low trend is possibly influenced by external forcing, for example, global warming, volcanism, and/or solar activity change.
\end{abstract}

\section{Introduction}

Over the last $50 \mathrm{yr}$, the Northern Hemisphere atmospheric circulation has undergone strong changes (Hoerling et al. 2001). The leading mode of winter variability in the North Atlantic is the North Atlantic Oscillation (NAO) and shows primarily interannual and decadal variability. Superimposed on this variability is a strong trend toward its positive phase from the 1950s to around the mid-1990s (Hurrell et al. 2003). In consequence, the westerly flow toward Europe is enhanced, the cyclone tracks (Raible and Blender 2004) and associated precipitation are shifted northeastward, and the temperature is higher than usual in central and northern Europe (Hurrell et al. 2003, and references therein). Vertically the NAO has an equivalent barotropic structure from the surface to the stratosphere

Corresponding author address: C. C. Raible, Physics Institute, University of Bern, Sidlerstrasse 5, CH-3012 Bern, Switzerland. E-mail: raible@climate.unibe.ch
(Wallace and Gutzler 1981; Thompson et al. 2000). Parallel to the recent NAO trend, the winter variability in the North Pacific region with its dominant equivalent barotropic Aleutian low (AL) shows a significant negative trend, associated with a warming of western North America and large-scale precipitation changes over Alaska and the west coast of North America (Trenberth and Hurrell 1994). Thus, the NAO trend to its positive phase and the negative trend of the Aleutian low contribute substantially to the observed midlatitude warming of the Northern Hemisphere. A better understanding of this trend behavior of large-scale circulation modes is essential in order to distinguish internal and externally forced variability, for example, the greenhouse gas increase, volcanism, and/or solar irradiance changes.

To first order, the structure of both patterns, the NAO and the Aleutian low, can be traced back to internal atmospheric dynamics, as they are identified in atmospheric general circulation models (GCMs) with fixed boundary conditions (Barnett and Preisendorfer 
1987; Saravanan 1998). The temporal evolution of these modes shows a nearly red-noise (random) behavior with an $e$-folding time of approximately 10 days for the NAO index (Wunsch 1999; Feldstein 2000). This is also demonstrated in a modeling intercomparison by Stephenson (2003) utilizing a temperature-based NAO index in 17 different models. However, the wavelet power spectrum of the observed and modeled NAO index indicates that there are time periods with distinct enhanced decadal variations (Pozo-Vázquez et al. 2001; Raible et al. 2001, 2004), as well as strong trends, like those observed in the last $50 \mathrm{yr}$ (Hoerling et al. 2001). These temporal features might be caused by physical processes rather than pure randomness. Proxy NAO reconstructions show that trends like the observed one probably have emerged a few times during the last few centuries (Appenzeller et al. 1998, hereafter A98; Glueck and Stockton 2001; Luterbacher et al. 2002a; Cook et al. 2002). At present it is still not clear whether or not there are dominant underlying mechanisms that are responsible for the formation of long-term trends in the Northern Hemisphere atmospheric circulation.

Up to now, several working hypotheses have been put forward in the literature to understand long-term variations of the NAO (Latif 1998; Wanner et al. 2001; Marshall et al. 2001b; Kushnir et al. 2002). One starting point is that external forcings, for example, global warming and/or insolation, influence the dominant modes in the Northern Hemisphere. Within this hypothesis, radiative forcing by greenhouse gas concentration and insolation changes interact with stratospheric dynamics (Shindell et al. 1999, 2001, 2003). The equator-to-pole temperature gradient is enhanced by radiative forcing, leading to an intensification of the zonal winds in the lower stratosphere and polar vortex (Perlwitz and Graf 2001).

Other studies emphasize the ocean and its coupling to the atmosphere to be important for long-term modulations of the dominant atmospheric modes. Performing a series of idealized ocean model experiments, a broad ocean response maximum to the NAO-like wind forcing on decadal time scales is found for the subpolar gyre (Visbeck et al. 1998). Analyzing coupled GCM simulations, a coupled atmosphere-ocean (AO) mode is evident in both basins, the North Pacific (Latif and Barnett 1994) and the North Atlantic (Grötzner et al. 1998). In their concept, the subpolar gyre responds to wind field variations. Then, the ocean is able to feed back to the atmospheric fields, creating longer time scales in the atmosphere. Moreover, Timmermann et al. (1998) described a coupled oscillation between the thermohaline circulation and the NAO on time scales of about $30 \mathrm{yr}$ in a coupled GCM simulation.
Another possible mechanism is a link between the El Niño-Southern Oscillation (ENSO) and the NAO that is proposed in observational studies on interannual time scales (Rowntree 1972; Fraedrich 1994). For strong El Niño phases, the North Atlantic storm-track tail is shifted southward leading to positive pressure anomalies over northern Europe and negative ones over central Europe (Fraedrich and Müller 1992). These observational findings are also confirmed in modeling studies (May and Bengtsson 1999; Cassou and Terray 2001; Merkel and Latif 2002).

Recently, Hoerling et al. $(2001,2004)$ and Hurrell et al. (2004) presented a hypothesis that simultaneous changes in precipitation and atmospheric heating triggered by the warming of the tropical Pacific Ocean, especially the Indian Ocean and the warm-pool region, may play an important role in producing the observed climate trend over the North Atlantic in combination with internal variability. They hypothesize further that the warming might be related to external forcing such as the increase of greenhouse gas concentrations.

Whether or not the anthropogenic increase in greenhouse gas emissions has an influence on the recent NAO trend behavior is still under debate. Collins et al. (2001), Gillett et al. (2003), and Osborn (2004) report that the rate of change of NAO in the last decades is inconsistent with the internal variability employing coupled and forced GCMs whereas Schneider et al. (2003), analyzing forced GCM simulations from 1950 onward, came to the conclusion that the observed NAO trend is consistent with internal variability. In these simulations an NAO link to the warming trend of the tropical SSTs in the warm-pool region was not found. Moreover, Osborn (2004) analyzed simulations from seven models forced by a compounded $1 \%$ per year increase in effective $\mathrm{CO}_{2}$. The sea level pressure trend patterns differ strongly among the simulations though the pattern-based NAO indices show a clear shift to the positive phase of the NAO.

The aim of this study is to investigate to what extent the observed Northern Hemisphere atmospheric circulation trends can be explained by internal variability in the coupled ocean-atmosphere system and whether or not the trend behavior in the two regions of the Atlantic and the Pacific are connected with each other. Therefore, we analyzed different coupled atmosphereocean model simulations for present-day climate conditions (Legutke and Voss 1999; Kiehl et al. 1998) and compared these with observed and reconstructed data (Kalnay et al. 1996; Kistler et al. 2001; Luterbacher et al. 2002b; Casty et al. 2005). In agreement with the findings of Schneider et al. (2003), our results suggest that the observed positive winter trend of the NAO can 
be produced naturally by atmosphere-ocean interaction, but a concomitant occurrence of a negative winter trend of the Aleutian low with its tropical connection is possibly influenced by external forcing.

The outline of the paper is as follows: First the datasets are described in section 2. Then, section 3 illustrates the atmospheric circulation trend behavior of the Northern Hemisphere and highlights possible origins. Finally, conclusions are given in section 4 .

\section{Data and analysis techniques}

\section{a. Datasets}

Because circulation modes of the Northern Hemisphere are dominant in winter, we selected means from December-January-February (DJF) to form the basis of our analysis. The data used in this study are divided into three parts:

- Observations: National Centers for Environmental Prediction-National Center for Atmospheric Research (NCEP-NCAR) reanalysis (Kalnay et al. 1996; Kistler et al. 2001) dataset covers the period from 1948 to 2000. Moreover, traditional stationbased index time series of the NAO (Hurrell 1995; available online at http://www.cgd.ucar.edu/cas/ jhurrell/indices.data.html) from 1865 to 2002 and the Aleutian low (available online at http://www.pac. dfo-mpo.gc.ca/sci/sa-mfpd/downloads/alpi.txt) from 1900 to 2002 (Beamish et al. 1997) are used.

- Reconstructions: The 500-hPa geopotential height using long instrumental and documentary proxy data back to 1659 (Luterbacher et al. 2002b; Casty et al. 2005; online at ftp://ftp.ngdc.noaa.gov/paleo/historical/ north_atlantic/500hpa_1659-1999.txt) ${ }^{1}$ as well as reconstructions of NAO indices (Cook et al. 2002; A98) are investigated. For the Aleutian region, only proxy index reconstructions of the Pacific decadal oscillation (PDO; available online at http://www.ngdc. noaa.gov/paleo/pubs/biondi2001/biondi2001.html) and the Pacific-North America (PNA; available online at ftp://ftp.ncdc.noaa.gov/pub/data/paleo/icecore/ trop/mtlogan/mtlogan.txt) pattern are available (Biondi et al. 2001; Moore et al. 2002). As the observations are limited to the short instrumental period of the last $140 \mathrm{yr}$, the use of the reconstructions is essential in order to achieve statistically meaningful results.

- Two different coupled AO simulations for presentday climate conditions (fixed to 1990): the first model

\footnotetext{
${ }^{1}$ Note that the data are reconstructed similarly to the sea level pressure in Luterbacher et al. (2002b).
}

configuration (denoted as ECHO-G in the following) consists of the fourth version of the European Centre model of Hamburg (ECHAM4) with a horizontal resolution of $\mathrm{T} 30\left(\sim 3.75^{\circ} \times 3.75^{\circ}\right)$ and 19 levels in the vertical coupled to the Hamburg ocean model in primitive equations (HOPE) with a horizontal resolution of $\sim 2.8^{\circ} \times 2.8^{\circ}$ and 20 vertical levels (Roeckner et al. 1996; Wolff et al. 1997). A 1000-yr longterm simulation is performed by introducing an annual mean flux correction scheme for heat and freshwater (Legutke and Voss 1999). The atmospheric regime behavior of this model run was investigated by Weisheimer et al. (2001). The second setup is the Climate Community System Model (CCSM), version 2.0.1 (see http://www.ccsm.ucar.edu/models/) developed by the NCAR (Kiehl et al. 1998). In the present study, the atmospheric part of this coupled model has a horizontal resolution of $\mathrm{T} 31\left(\sim 3.75^{\circ} \times\right.$ $3.75^{\circ}$ ) with 26 levels in the vertical; the ocean has $\sim 3.6^{\circ} \times 1.8^{\circ}$ with 25 levels. While ECHO-G uses an annual flux adjustment, the CCSM runs without any flux corrections. The CCSM is integrated in total for $800 \mathrm{yr}$ on two different computer platforms, an IBM SP4 and a Linux cluster (Renold et al. 2004).

\section{b. Analysis techniques}

To characterize the leading modes and their temporal behavior, indices are defined for the observations, the reconstructions, and the simulations in two sectors, the North Atlantic and the North Pacific: In the North Atlantic an empirical orthogonal function (EOF) analysis is applied to the $500-\mathrm{hPa}$ geopotential height data from the area $25^{\circ}-70^{\circ} \mathrm{N}, 90^{\circ} \mathrm{W}-40^{\circ} \mathrm{E}$ (shown for the NCEP-NCAR reanalysis data in Fig. 1). The principal component of the first EOF is used as a substitute for a NAO index. Note that for the reconstructions (Luterbacher et al. 2002b), the index is derived from the area $30^{\circ}-70^{\circ} \mathrm{N}, 30^{\circ} \mathrm{W}-40^{\circ} \mathrm{E}$. However, the influence of this reduced area is negligible. ${ }^{2}$ For the North Pacific with its dominant $\mathrm{AL}$, a normalized weighted area $\left(45^{\circ}-\right.$ $55^{\circ} \mathrm{N}, 175^{\circ}-165^{\circ} \mathrm{W}$ ) index is derived from the $500-\mathrm{hPa}$ geopotential height similar to the technique of Beamish et al. (1997). This simple technique is preferred over an EOF analysis (which is traditionally applied to the Pacific-North America region) because it ensures that

\footnotetext{
${ }^{2}$ This was checked within the NCEP data for 1949-2000, showing that an NAO index derived for the reduced area has an almost identical temporal behavior as an NAO index using the classical Atlantic sector from $25^{\circ}-70^{\circ} \mathrm{N}, 90^{\circ} \mathrm{W}-40^{\circ} \mathrm{E}$. Moreover, a "stationbased" index (Hurrell 1995) agrees with the behavior of an NAO index based on the EOF technique.
} 
(a)

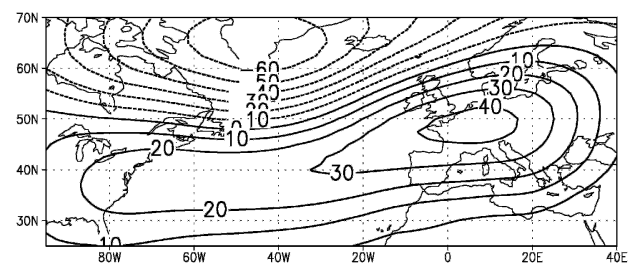

(b)

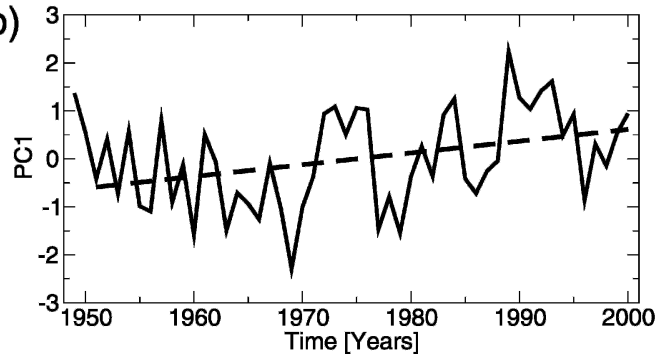

(c)

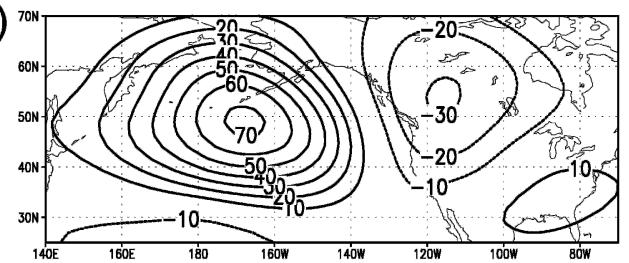

(d)

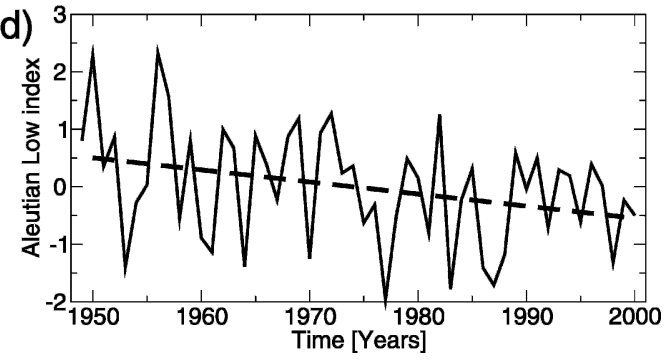

FIG. 1. (a) The leading EOF (EOF1) of observed 500-hPa geopotential height for the North Atlantic sector in winter (DJF) over the period 1949-2000 from NCEP-NCAR reanalysis data. The EOF1 explains $41 \%$ of the total 500-hPa geopotential height variance over this region. The spatial pattern of the EOF1 describes the NAO, shown in its "positive" phase (the contour increment is $10 \mathrm{gpm}$ ). (b) The corresponding principal component time series of EOF1. The linear trend (1951-2000) in this time series is shown as a dashed line. (c) The regression pattern of the AL index with the 500-hPa geopotential height (the contour increment is $10 \mathrm{gpm}$ ). (d) Time series of the AL index; dashed line is the linear trend (1951-2000).

only variability of the North Pacific is captured. Nevertheless, index time series based on an EOF analysis are similar to those derived from a normalized weighted area. The index time series of the station-based observations, the reconstructions, and the simulations are used to identify periods with strong trends. A 50-yr running window is applied, and the linear trend is estimated within each window. From this, 50-yr trend time series of the NAO and AL indices are derived.

The simulated trend time series are employed in a composite analysis to identify the mean trend behavior in phases with strong positive $\mathrm{NAO}$ and negative $\mathrm{AL}$ trends. In a first step, the trend pattern evolution of a variable (e.g., $500-\mathrm{hPa}$ geopotential height or $250-\mathrm{hPa}$ zonal wind) is estimated applying again a 50-yr running window and estimating the linear trend of every grid point. In a second step, all trend patterns that exceed +1 standard deviation of the NAO trend time series and undershoot -1 standard deviation of the AL trend time series are averaged. This yields a mean trend pattern of the corresponding variable when either a strong positive NAO trend or a strong negative AL trend is present.

The composites are statistically tested with a standard Student's $t$ test, where the null hypothesis is that the mean trend pattern is zero (von Storch and Zwiers 1999). The significance level is set to $99 \%$. For the observations (NCEP-NCAR reanalysis), a second testing procedure is necessary because there is only one realization of a 50-yr trend. This test of the slope parameter compares an estimated trend at each grid point with the null hypothesis that the trend parameter is zero. Details can be found in von Storch and Zwiers (1999).

Both simulations are analyzed separately. Then, the results are merged to mean composites. In this sense, a multimodel approach is used. The statistical testing is applied to the merged datasets. As the two models have statistically different properties, we do not interpret regions where differences between the models' statistical properties (e.g., mean and variance) are obvious. Additionally, applying the testing separately to the models, regions that are not statistically significant in one of the model simulations are ignored.

\section{Results}

To investigate the influence of the internal atmosphere-ocean variability on the observed Northern Hemispheric circulation trends, the dominant observed modes are presented and the trend behavior of the corresponding observed, reconstructed, and simulated index time series are discussed in a first step. Second, the observed hemispheric trend characteristic is compared to the simulated mean trend pattern. Finally, possible origins of the trends in atmospheric circulation caused by internal atmosphere-ocean climate variability are described.

\section{a. Modes and trends in index time series}

According to the analysis techniques mentioned above, index time series are calculated for observations, 
reconstructions, and simulations. As an example, the leading winter (DJF) EOF of the North Atlantic, which defines the NAO index, is shown in Fig. 1a for NCEPNCAR reanalysis data. The pattern illustrates a positive NAO phase with a strong Icelandic Low and an intensified Azores High. This mode explains $41 \%$ of the total 500-hPa geopotential height variance over this region. Datasets based on the model simulations exhibit very similar structures and explained variances (ECHO-G: 39\%; CCSM: $37 \%$ of this first mode). The first principal component (Fig. 1b) shows a strong positive trend $(+1.23$ index change in $50 \mathrm{yr})$ superimposed on interannual and decadal variations. In the North Pacific area, the pattern related to the AL index time series is illustrated by a regression pattern to the 500hPa geopotential height (Fig. 1c). This pattern has a PNA structure; again the simulations behave spatially in a similar manner with centers of action at nearly the same position as for the observations (NCEP-NCAR reanalysis). Temporally we find a strong negative trend (-1.12 index change in $50 \mathrm{yr}$; Fig. 1d) of the AL index over the last $50 \mathrm{yr}$. For the simulations, both index time series resemble the range of the observed variability as well as the extreme index values (Figs. 2a,b). To exclude trends caused by model adjustment at the beginning of each simulation, the first $50 \mathrm{yr}$ are ignored for the analysis.

To investigate trends of leading circulation modes in the Northern Hemisphere, we turn to the 50-yr trend time series. Note that moderate window size changes, for example, $40 \mathrm{yr}$, have no influence on the following findings. For the intercomparison of these time series, the corresponding probability density functions (PDFs) are calculated (Fig. 3). For the instrumental period (Fig. 3a), the PDF of the NAO indicates a bimodal structure. However, this may be due to the limited sample size. Nevertheless, the standard deviation (not shown) of the distributions of the simulated 50-yr NAO trends resembles the observation (Figs. 3b,c, left). Note that the observed large NAO trend is a rare event also in the simulations where it appears less than $2.5 \%$ in the ECHO-G runs (and less than $1.5 \%$ in CCSM). Again this is in agreement with the observed PDF, where one has to consider that the observational time series is short compared to the model simulations and therefore could overestimate the occurrence of such large trends. For the 50-yr trends of the AL index, both simulated distributions (Figs. 3b,c, right) have a decreased standard deviation (not shown) compared to the observation. This is possibly associated with an underestimation of low-frequency ENSO variability in both models. The correlation between NAO and AL trend time se- (a)
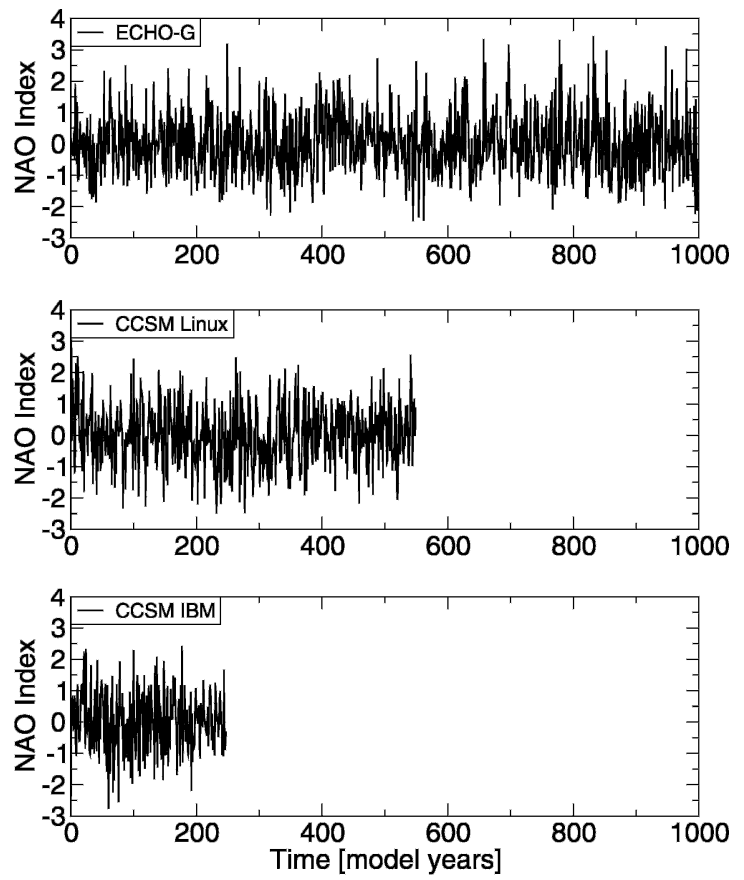

(b)
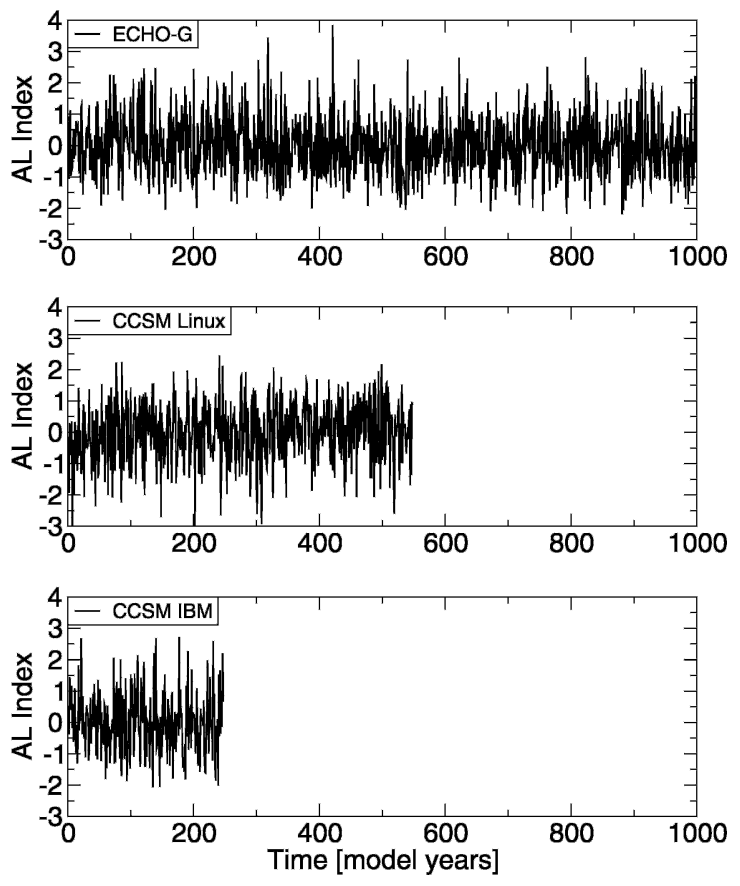

FIG. 2. Simulated winter (DJF) time series for the (a) NAO and (b) AL index for the ECHO-G, the CCSM simulation on the local Linux cluster, and the CCSM simulation on the IBM.

ries for both simulations is less than 0.1. Thus, the observed simultaneous appearance of a positive NAO and a negative AL trend is a rare and unlikely event. Moreover, the analysis of an atmosphere-only simulation (ECHAM4 forced for $110 \mathrm{yr}$ by climatological SSTs) shows that for both indices the standard deviation is 

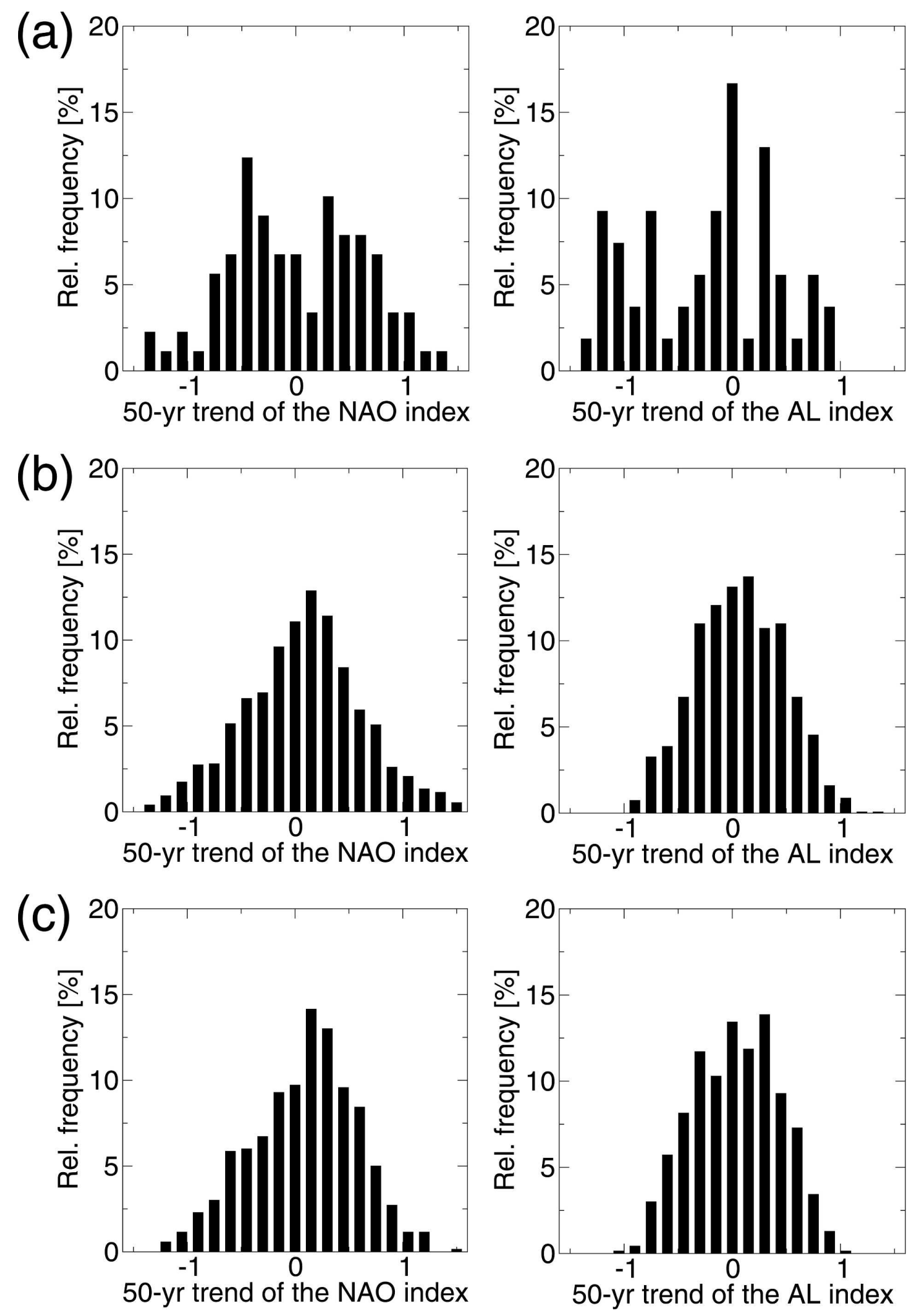

FIG. 3. PDFs of the 50-yr winter (DJF) trends in (left) the NAO and (right) the AL index: (a) station-based observations (Hurrell 1995; Beamish et al. 1997), (b) ECHO-G, and (c) CCSM simulations. Note that the simulated PDFs are based on the 500-hPa geopotential height data, whereas the station-based observations refer to the sea level pressure. 
(a)
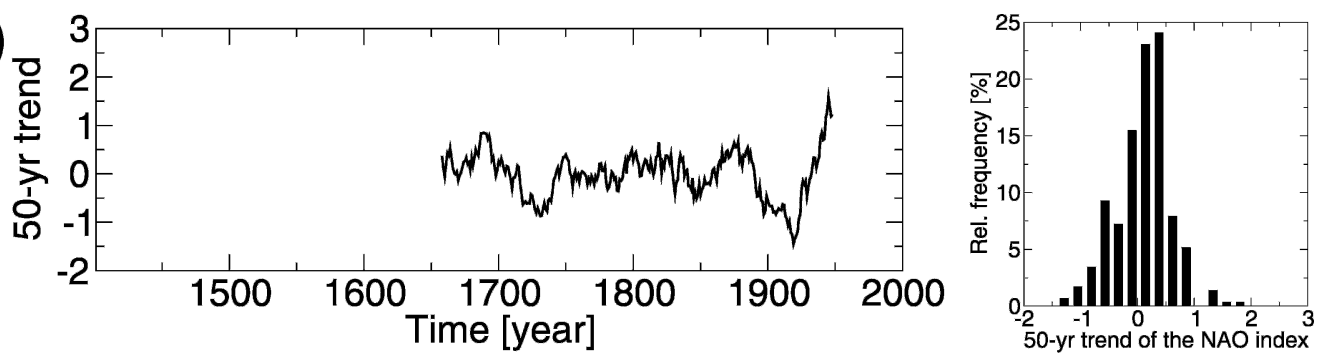

(b)
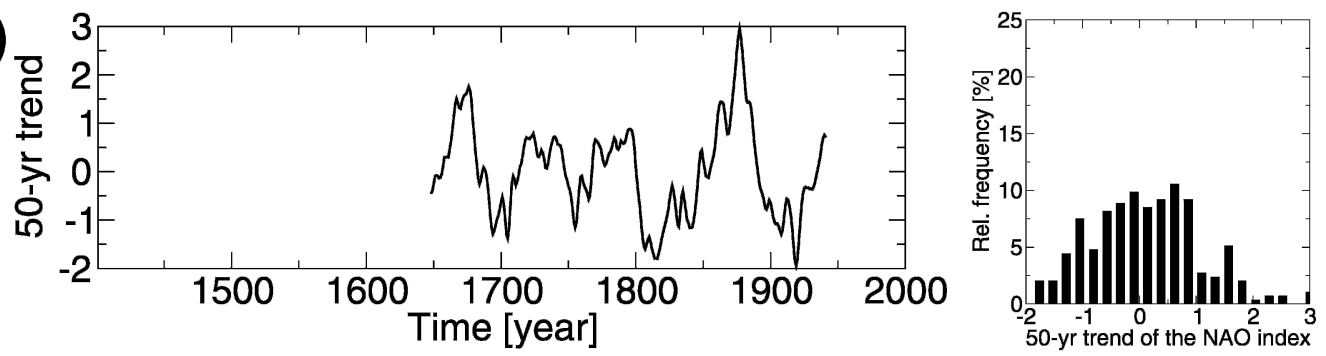

(c)
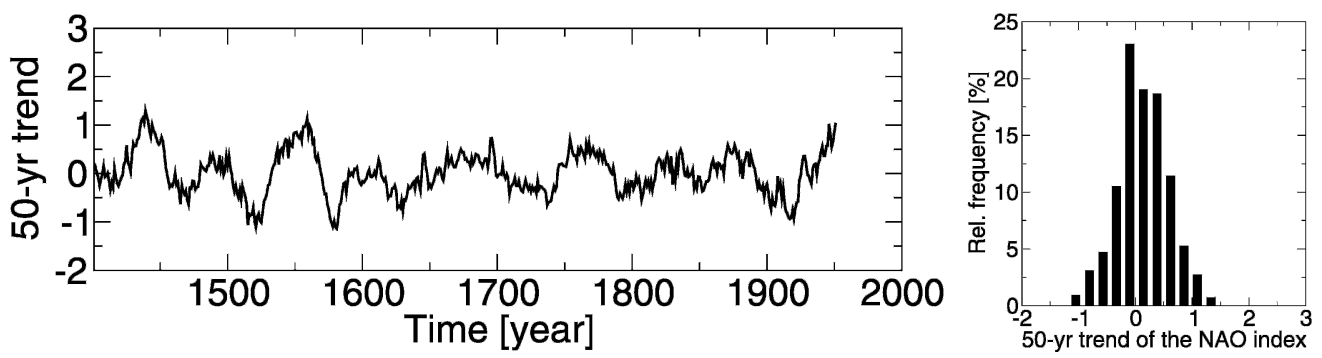

FIG. 4. 50-yr winter trend (left) time series and (right) PDFs for reconstructed NAO indices: (a) Luterbacher et al. (2002b), (b) A98, and (c) Cook et al. (2002). In the left panels, trends are assigned at the beginning, so that the last point in (a) is the linear trend for the period 1953-2002. Note that the Luterbacher index is derived from the 500-hPa geopotential height reconstruction (winter DJF), whereas the other two indices are proxies for the NAO index. The Appenzeller proxy is an annual index from spring to spring; the Cook NAO index is a mean of Dec to Mar.

smaller than in the coupled GCM simulations, suggesting that the ocean has an impact on the range of trend variability.

\section{b. Reconstructed trend behavior}

To substantiate our findings in the modeling approach, index and field reconstructions of the past centuries allow us to increase the limited sample size of the instrumental observations.

For paleo-reconstructions of the NAO, several indices are proposed in the literature, for example, A98, Cook et al. (2002), and Luterbacher et al. (2002b). The trend analysis is applied to these time series. The resulting trend time series and the corresponding PDFs are displayed in Fig. 4. The comparison with the observations show that the Luterbacher (based on the leading mode of the 500-hPa geopotential height; Fig. 4a) and the Cook reconstruction (a normalized sea level pressure NAO index; Fig. 4c) behave similarly: both proxy indices have strong (positive and negative) trends at nearly the same time, for example, around 1690 and between 1750 and 1800. However, for the preinstrumental period, the strength of these trends is reduced for the Luterbacher reconstruction, which is illustrated by the increased relative frequencies of the PDFs around zero. This can be traced back to the regression methods used for the derivation of the proxy data that underestimate extreme values (Luterbacher et al. 2002a). Note that the instrumental period is used to fit regression techniques for building the reconstructions. The outlier of these reconstructions is the A98 NAO (Fig. 4b), which overestimates the positive trend in the late nineteenth century (within the instrumental period). Comparing this index to the two other reconstructions in the preinstrumental period, trends of the A98 NAO proxy index behave differently. For instance, around 1690 the A98 NAO shows a negative trend 
whereas the two other proxy NAO indices indicate a positive trend. The reason for these discrepancies is that $\mathrm{A} 98$ use the normalized accumulation rate in northwest Greenland as the NAO index, which is influenced by the NAO but also contains regional and other variability. Tests in the model environment using a similar approach (a normalized precipitation index averaged over the same region as A98) show that at least in one model (ECHO-G) similar strong trends (more than +3 index change in $50 \mathrm{yr}$ ) are found. Moreover, the A98 NAO proxy index is an annual index whereas Luterbacher and Cook derived a winter proxy index for DJF 500-hPa geopotential height field and DJF-March (DJFM) sea level pressure difference, respectively.

For the Pacific, a reconstruction of the winter AL variability is unfortunately not yet available. One proxy of this region, which is connected with AL variability, is the PDO reconstruction based on tree rings (Biondi et al. 2001), and therefore it is dominated by summer variability. A second proxy is the PNA reconstruction (Moore et al. 2002) using the annual snow accumulation at the Mount Logan site. For both proxy reconstructions, the trend time series show no simultaneous occurrence of positive NAO (reconstruction of Luterbacher and Cook) and negative AL trends, except for the instrumental period from 1865 to 2000 . This suggests that the modeling results of the unlikely and rare simultaneous appearance of a positive NAO and negative AL trends may be realistic. Still, caution has to be exercised: as mentioned in Moore et al. (2002), even the reconstructions of the PDO and PNA show a different behavior before and during the instrumental period.

\section{c. Northern Hemispheric trend pattern}

To gain insights into the atmospheric circulation trend behavior on the Northern Hemispheric scale, patterns are derived from the NCEP data and the simulations. The $500-\mathrm{hPa}$ geopotential height trend pattern (DJF), presented by Hoerling et al. (2001), shows strong negative trends south of Greenland and positive trends near the Azores and over Europe (Fig. 5). In addition, a negative trend at the Aleutian Islands and a positive trend over western Canada are observed. Note that only the strongest features are significant at a level of $95 \%$ because of the high interannual variability in this region.

This observed pattern is compared with the simulated mean composite of the 50-yr trend pattern for phases with positive NAO (exceeding +1 standard deviation) and negative AL trends (undershooting -1 standard deviation; Fig. 6). For the simulated positive NAO trend composite, clearly a strong negative trend

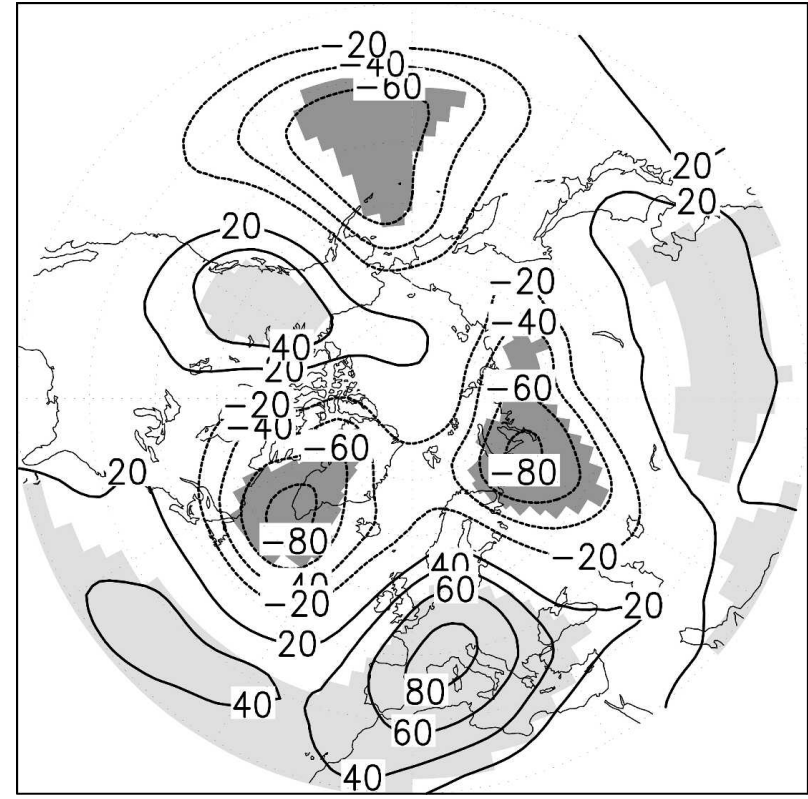

FIG. 5. The Northern Hemisphere 500-hPa geopotential height 50 -yr trend pattern for the region $25^{\circ}-87^{\circ} \mathrm{N}$ in winter (DJF) $1951-$ 2000 using the NCEP-NCAR reanalysis (Hoerling et al. 2001). Dark shading indicates negative values that are significant at the 95\% level (testing procedure is described in section 2); light shading indicates significant positive values. The contour increment is 20 gpm per $50 \mathrm{yr}$.

near Iceland and a strong positive trend of the Azores high is found in the geopotential height fields (Fig. 6a). These trends have a barotropic structure illustrated by the trend pattern of the 1000-hPa geopotential height (Fig. 6c). In contrast to the observations, the simulations show a small positive trend near the Aleutian Islands in the case of strong positive NAO trends, so that the whole hemispheric trend pattern has an annular mode structure (Thompson et al. 2000).

For the simulated negative AL trend composite of the geopotential height fields (Figs. 6b,d), a PNA-like pattern is identified with its centers near the Aleutians, over western Canada and Florida. At least the first two centers of action are also present in the observations. In the North Atlantic, a very weak trend toward the negative phase of the NAO (a weaker Azores High and Icelandic Low) is indicated, which is opposite to the observational findings.

The strength of the patterns cannot be compared to the observed one in Fig. 5 because of the averaging over cases with different trend amplitudes. The largest of the simulated trend patterns, however, still underestimates the observed geopotential height difference of $160 \mathrm{gpm}$ between Iceland and the Azores by approximately $10 \%$. Possible reasons may be the absence of external forcings as well as the coarse vertical resolution, which 
Positive NAO trend

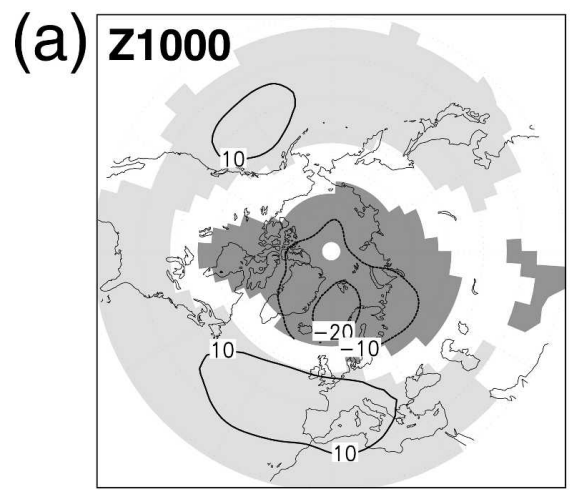

(c)

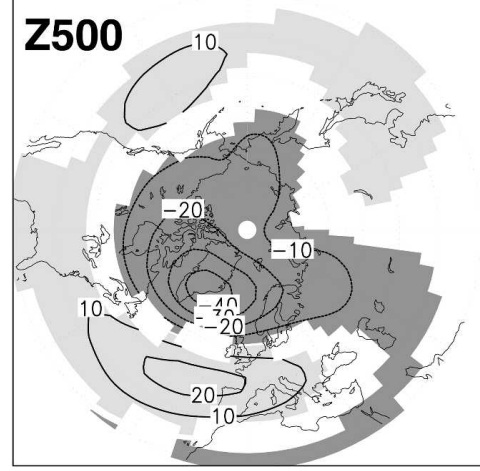

Negative AL trend
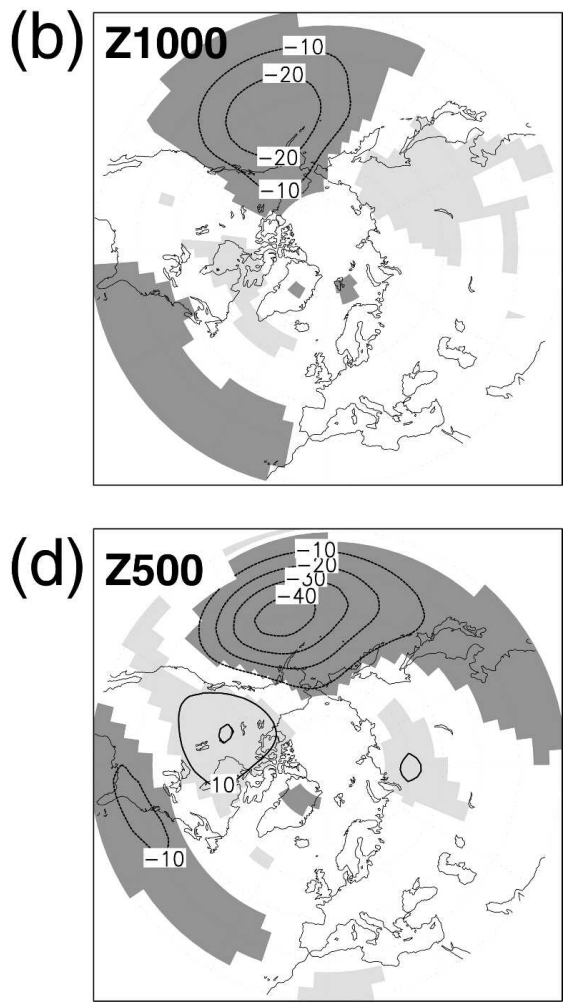

FIG. 6. Mean simulated 50-yr trend pattern averaged over both model simulations (ECHO-G and CCSM) for winter (DJF): (a), (b) 1000- and (c), (d) 500-hPa geopotential height $\left(0^{\circ}-87^{\circ} \mathrm{N}\right)$ for phases (a), (c) where the NAO 50-yr trends exceed more than $1 \mathrm{std}$ dev and (b), (d) where the AL 50-yr trends exceed -1 std dev. Dark shading indicates negative values that are significant at the $99 \%$ level; light shading indicates significant positive values. The contour increment is $10 \mathrm{gpm}$ per $50 \mathrm{yr}$.

leads to an underrepresentation of the stratospheric processes. Stratospheric processes themselves can be influenced by changes in the external forcing (Shindell et al. 1999, 2001, 2003; Perlwitz and Graf 2001; Walter and Graf 2002). Moreover, the coarse horizontal model resolution can be responsible for the discrepancies, for instance, a reduction of cyclone track density is reported by Blender and Schubert (2000) if the horizontal resolution is decreased.

From this point of view, one can conclude that 50-yr trends of Pacific and North Atlantic circulation modes caused by internal variability are not connected with each other. However, in the model simulations, positive NAO trends go along with a positive trend near the Aleutian Islands. The observation itself is one realization and includes all kinds of external forcings and mechanisms that are not (or not fully) represented in the model simulations. The unlikely and simultaneous occurrence of trends in the observations is a hint that at least one mode, either the NAO or the AL, may be influenced by external forcings, whereas the other may be of purely internal atmosphere-ocean origin and occurred randomly at the same time.

\section{d. Origin of trends}

There is a variety of working hypotheses invoking different processes to explain the circulation trend pattern. In our model simulations, changes in external forcings are absent, and stratospheric processes are not well represented because of the coarse model resolution. The ocean and its interaction with the atmosphere remains a possible candidate for the development of long-term trends.

In the case of positive NAO trends, the composite of sea surface temperature (SST) shows a strong cooling of the Labrador and Greenland Seas (Fig. 7a). The typical tripole SST pattern that is normally associated with the NAO (Wu and Gordon 2002) is only slightly indicated. By decreasing the significance level to $95 \%$, a clear positive SST trend between $30^{\circ}$ and $40^{\circ} \mathrm{N}$ emerges 

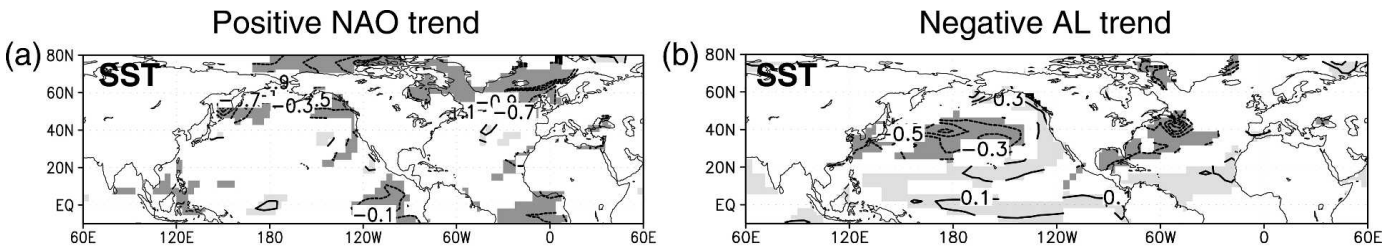

(c)
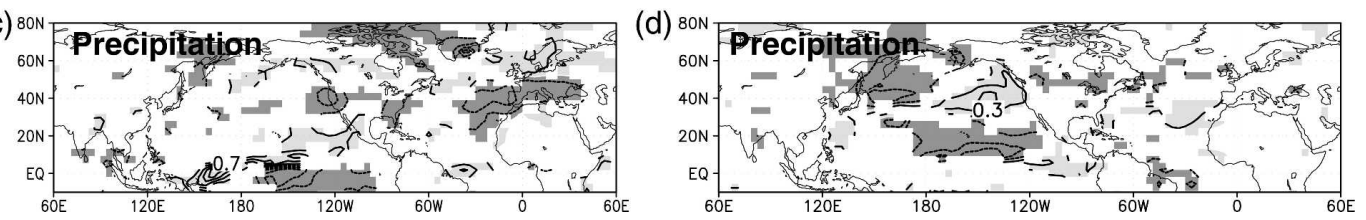

FIG. 7. Same as in Fig. 6, but for (a), (b) SST and (c), (d) precipitation. Note that the land-sea mask from the ECHO-G simulation is used for the SST. The contour increment is $0.2 \mathrm{~K}$ per $50 \mathrm{yr}$ for the SST and $0.2 \mathrm{~mm} \mathrm{day}^{-1}$ per $50 \mathrm{yr}$ for precipitation.

in the Atlantic and a small cooling trend emerges near Africa. This tripole pattern is also observed for the period 1951-2000 (Wu and Gordon 2002). In the Pacific, a cooling trend north of $50^{\circ} \mathrm{N}$ is evident, but the tropical Pacific and the Indian Ocean show nearly no large-scale trend patterns, suggesting that ENSO-like variability is not strongly involved in generating positive NAO trends. As mentioned above, the atmosphere-only simulation shows that the range of NAO trends is decreased corroborating the ocean's impact to the simulated NAO trend behavior.

For a better understanding, we turn to the atmospheric wave behavior. The composite of total precipitation (Fig. 7c), which is connected with the cyclone tracks in the midlatitudes and therefore to the eddy activity (Hurrell and van Loon 1997; Sickmöller et al. 2000), shows a strong northward shift at the tail of the Atlantic storm track. Over southern Europe, the rainfall is reduced, whereas positive precipitation trends are found in Scandinavia. The strong changes in the tropical Pacific cannot be interpreted because both models show different results; the pattern shown in Fig. 7c is dominated by the ECHO-G model, which simulates in the Tropics stronger precipitation trends than the CCSM. Even the long-term means of both models deviate strongly in this region (not shown). The $250-\mathrm{hPa}$ zonal wind shows that the so-called eddy-driven jet (near $50^{\circ} \mathrm{N}$ ) is enhanced whereas the subtropical jet is decreased in the North Atlantic (Fig. 8a). This underlines that the changes of precipitation are associated with eddy activity in the midlatitudes.

Moreover, the stationary waves, here illustrated by the 250-hPa streamfunction with its zonal mean removed (denominated as $250-\mathrm{hPa}$ streamfunction in the following; Fig. 8c), indicates a clear NAO-like stationary wave over the Atlantic but no pronounced structure over the Pacific. This again suggests that NAO trends could evolve without any changes in the Pacific and the ENSO region. Thus, we conclude that both the North Atlantic Ocean and the atmospheric wave activity of the North Atlantic contribute to the formation and strengthening of the simulated NAO trends.

For strong trends of the AL index, the SST composite shows a pattern (Fig. 7b) that is similar to the PDO with strong negative trends in the central North Pacific and positive trends near the west coast of North America (Mantua et al. 1997). In addition, a positive trend is visible in the ENSO region. Thus, if a strong negative trend of the Aleutian low is found, ENSO shows a trend to its positive phase. This is in agreement with findings from Meehl and Washington (1996). In the North Atlantic, the SST shows a strong negative trend at the east coast of North America, which is not interpreted because of deviations comparing both model simulations: ECHO-G has strong negative trends in the western part and positive trends in the eastern part of the North Atlantic, whereas CCSM shows no strong trends in the Atlantic. Again, the model simulations exhibit some evidence that negative AL trends are associated with the underlying SST and with ENSO, but there is no clear connection to the Atlantic.

To illustrate the connection between ENSO and the Aleutian low, the wave activity is investigated. The zonal wind in $250 \mathrm{hPa}$ (Fig. 8b) shows a strengthening and a southward shift of the subtropical jet maxima over the Pacific area. This is connected with an enhanced Hadley circulation, which is triggered by ENSO (Klein et al. 1999). The subtropical jet and Hadley cell variations trigger a planetary wave train (Hoskins and Karoly 1981; Horel and Wallace 1981), which is illustrated by the 250-hPa streamfunction given in Fig. 8d. A PNA-like wave train is found, which connects the ENSO phenomenon with the Aleutian low, but a con- 

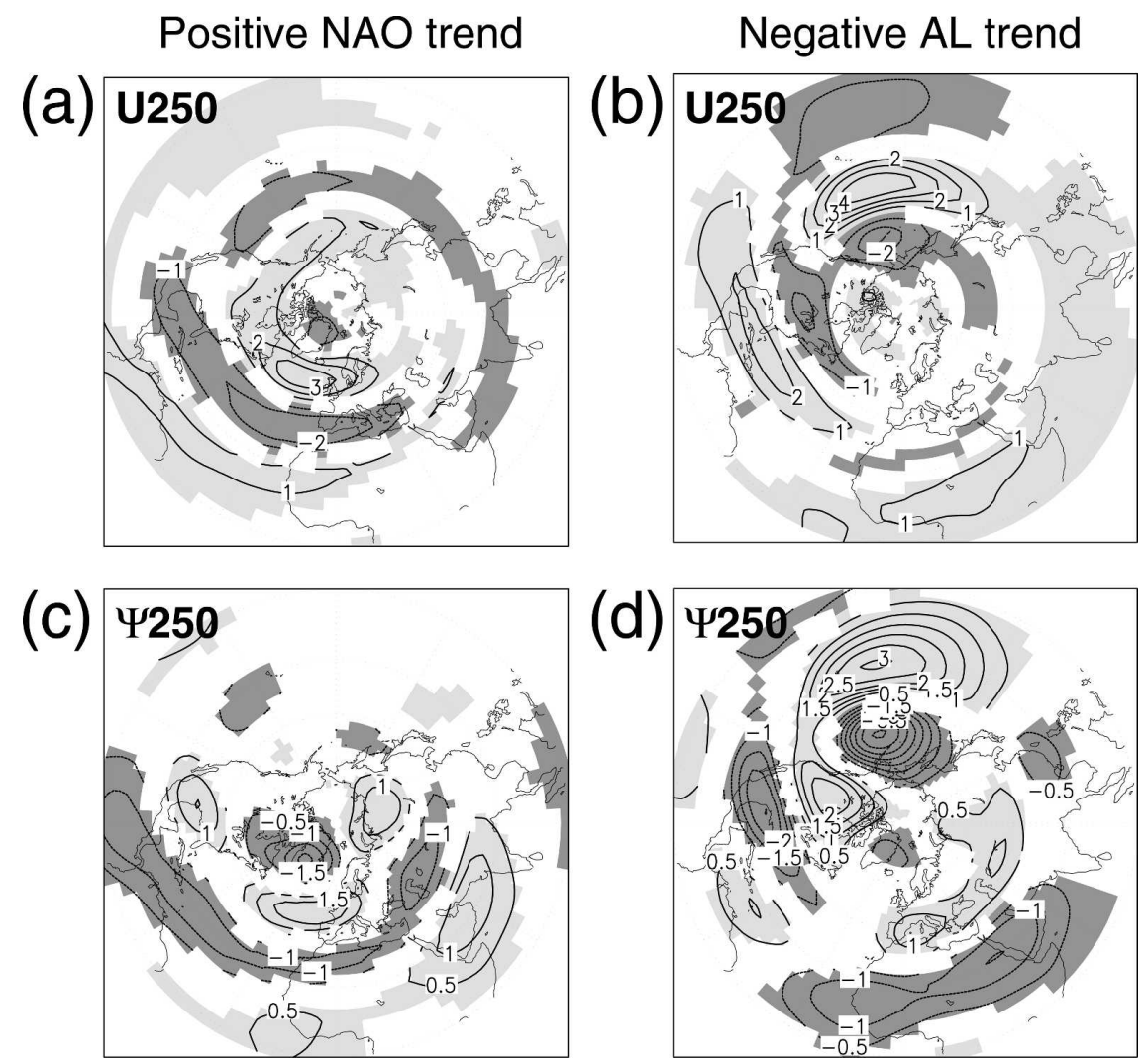

FIG. 8. Same as in Fig. 6, but for (a), (b) zonal wind in $250 \mathrm{hPa}$ and (c), (d) $250-\mathrm{hPa}$ streamfunction with its zonal mean removed. The contour increment is $1 \mathrm{~m} \mathrm{~s}^{-1}$ per $50 \mathrm{yr}$ for the zonal wind and $0.5 \times 10^{7} \mathrm{~m} \mathrm{~s}^{-2}$ per $50 \mathrm{yr}$ for the streamfunction.

nection to the Atlantic is again absent. The precipitation trend composite (Fig. 7d) for the AL index is unfortunately not interpretable in the tropical regions (as mentioned above), but for the midlatitudes a west-east dipole pattern is present in the Pacific, which could be interpreted in such a way that the cyclone activity is increased in the east and reduced in the west. This is supported by an observational study (Sickmöller et al. 2000) that shows that the cyclone density has two genesis regions in the Pacific-one near Japan and in the central North Pacific. The negative SST trends of the PDO-like pattern (Fig. 7b) reduce the land-sea contrast and therefore the baroclinicity, leading to a decrease in cyclone genesis in this region and thus a reduction of rainfall. In the central North Pacific, the PDO-like pattern shows a strong gradient that enhances the baroclinicity and increases the cyclone genesis. These cyclones travel eastward and can therefore strengthen the Aleutian low. Taking this into account, we conclude that both the stationary waves triggered by SST increase in the ENSO region as well as the eddies favored by the SST are involved in creating a negative trend near the Aleutian Islands.

\section{Discussion and conclusions}

Simulated winter atmospheric Northern Hemispheric trend patterns are investigated to better understand the observed atmospheric circulation trend behavior of the last $50 \mathrm{yr}$. Therefore, long-term coupled AO-GCM simulations for constant present-day climate conditions (1990) are investigated in a multimodel approach and compared to observations and proxy reconstructions.

Regarding the 50-yr trend behavior, one can conclude that the simulations are able to reproduce the observed trends in the normalized case of the indices with a slight $10 \%$ underestimation of extreme NAO trends in the nonnormalized case. Moreover, the analysis gives some evidence that the simultaneous appearance of a strong negative trend close to the Aleutians and a positive NAO trend is very unlikely to occur by chance. It seems that if there is a trend in one basin, for example, the North Atlantic, the contribution from the other basin (the Pacific) is negligible. The results suggest that under the absence of external forcing, decadal trends of the two pressure indices are unlikely to have 
a common origin. This is also found in analyses of the reconstructions for the preinstrumental period, but caution has to be exercised in the interpretation of the proxy results. Even the different reconstructions themselves deviate substantially in the preinstrumental period (Moore et al. 2002; Luterbacher et al. 2002a).

The multimodel approach shows that an NAO trend toward its positive polarity is strongly connected with the underlying ocean indicated by the well-known SST tripole pattern (Wu and Gordon 2002). The associated patterns of atmospheric eddy activity and stationary waves sustain this NAO trend. Note that this is supported by studies of sensitivity experiments with an atmospheric model of intermediate complexity that show that a cold thermal anomaly reinforces the Icelandic Low (Walter et al. 2001; Kushnir et al. 2002), leading to an equivalent barotropic response. Moreover, this response is strongly nonlinear and depends on the sign and position of the thermal forcing relative to the storm track in the North Atlantic (Peng and Whitaker 1999; Walter et al. 2001).

For strong negative trends of the AL, we find again a strong connection with the underlying ocean and the tropical Pacific. The mechanism of strengthening the AL consists of two major processes: a planetary wave train that is triggered by SST changes in the ENSO region resembling the expected linear response (Zhang et al. 1992) and an eastward shift of the eddy activity due to the increased baroclinicity in the central North Pacific caused by the PDO-like SST pattern. This eastward shift is also found in observations (Sickmöller et al. 2000).

Comparing the simulated trend behavior with the observed one, the causes of the trends in the simulated atmosphere-ocean system suggest that the observed AL trend is most likely influenced by external forcings via its ENSO relationship. The observed SST trend in the ENSO region may be related to external parameters, for example, greenhouse gases and insolation. This is supported by the fact that the simulated SST trend in the tropical Pacific, even in extreme negative $\mathrm{AL}$ trend cases, never reaches more than half of the observed SST trend of approximately $1.5^{\circ} \mathrm{C}$ per $50 \mathrm{yr}$ in the Niño-3 region. In a linear sense, the observed SST trend in the ENSO region could lead to a very strong negative trend close to the Aleutian Islands and could overlap the small positive trend, which is present when a positive NAO trend is detected because of internal atmosphere-ocean variability. Thus, the following hypothesis of the origin of the Northern Hemispheric trend pattern is proposed: The NAO trend is not statistically different from internal variability of the coupled regional atmosphere-ocean system and is "ac- cidentally" present by chance in the observations, whereas the trend of the Aleutian low is triggered by the warming in the ENSO region, which itself may be reinforced by external parameters, such as greenhouse gases and solar activity. Moreover this hypothesis is supported by the study of Schneider et al. (2003), which came to similar conclusions but used a different model, experimental design, and analysis techniques. However, analyzing some coupled simulations with a prescribed $1 \% \mathrm{CO}_{2}$ increase per year (not shown) in combination with the findings of Osborn (2004, his Fig. 5), a clear conclusion could not be presented. Some model simulations show a strong negative trend near the Aleutians whereas others show an NAO trend to its positive phase supporting the hypothesis that the Indian Ocean plays a role in the formation of the recent NAO trend (Hoerling et al. 2001).

To test this hypothesis, we analyzed the 50-yr trends of the Indian Ocean SSTs and their relation to the Northern Hemisphere atmospheric circulation. Therefore, an SST index as mean over the region $15^{\circ} \mathrm{S}-15^{\circ} \mathrm{N}$, $40^{\circ}-110^{\circ} \mathrm{E}$ is defined in all model simulations corresponding to the index definition in Hoerling et al. (2004). In all model simulations, approximately $7 \%$ (ECHO-G) and 8\% (CCSM2) of the trends are similar or stronger than observed $(\sim 0.6 \mathrm{~K}$ per $50 \mathrm{yr})$. Correlating the Indian Ocean SST trend time series (deduced in the same way as the NAO and the AL trend time series in section $2 b$ ) with the NAO trend time series, we find coefficients: -0.08 and -0.11 for the ECHO-G and the CCSM simulations, respectively. This shows that trend behaviors are not connected to each other in a linear sense in the two areas. To test a possible nonlinear relation, we make a composite of all 500-hPa geopotential height trend patterns, which exhibit a strong positive trend of the Indian Ocean SST (not shown). Overall the amplitudes are very weak, and a statistically significant NAO signature is not found in the North Atlantic region. This implies that positive SST trends of the Indian Ocean have a negligible contribution to the trend behavior of the North Atlantic region in these model simulations. Therefore, these modeling results do not support the hypothesis of Hoerling et al. (2001, 2004) and Hurrell et al. (2004).

The disagreement may be evoked by their experimental design (forced experiments) where damping processes as well as positive feedback loops (Latif and Barnett 1994; Grötzner et al. 1998; Marshall et al. 2001a; Raible et al. 2004) are not included. In contrast, we utilized coupled GCM simulations, which contain coupled atmosphere-ocean processes that are important for long-term variability. Moreover, Bretherton and Battisti (2000) show that one should be cautious in 
interpreting the variability of the coupled climate system in forced GCM simulations. They show that the air-sea fluxes are of reverse sign to those observed in ensemble GCM simulations forced by realistic SST anomalies that reproduce the long-term NAO variability (Rodwell et al. 1999). However, we have to indicate that the underestimation of the NAO trend of about $10 \%$ in the nonnormalized case leaves some space for a tropical (Hoerling et al. 2001) and/or a stratospheric contribution (Hartmann et al. 2000; Shindell et al. 2001, 2003) to the observed NAO trend. But a discrepancy of only $10 \%$ suggests that these processes are rather of second order. Even the coarse horizontal resolution might be responsible for this underestimation. Nevertheless, a further investigation of the stratosphere and a systematic study of the influence of the vertical resolution on the variability of the troposphere would be helpful.

The results of the reconstructions suggest that there is a necessity of field reconstructions, for example, the Northern Hemisphere, rather than simple indices. Furthermore, future reconstruction methods should be able to treat strong deviations from the mean better than the used linear regression techniques. Possible options are nonlinear methods, for example, analog schemes and/or neural networks.

Acknowledgments. Thanks are due to D. T. Shindell for discussions, the Model and Data Group (M\&D, Max-Planck-Institute for Meteorology in Hamburg, Germany) for providing the data of the ECHO-G longterm simulation and to the National Center for Atmospheric Research (NCAR) for making the CCSM available to the scientific community. This work is supported by the National Centre of Competence in Research (NCCR) on Climate funded by the Swiss National Science Foundation. Part of the simulations were performed at the Swiss Center of Scientific Computing (SCSC) in Manno, Switzerland. TFS acknowledges support by PACLIVA funded through Contract EVR12002-000413 and the Swiss Office of Education and Research. Moreover, JL acknowledges the project SOAP (Simulations, Observations and Paleoclimate Data: Climate Variability over the Last 500 Years) supported by the 5th framework Programme of the European Union.

\section{REFERENCES}

Appenzeller, C., T. F. Stocker, and M. Anklin, 1998: North Atlantic Oscillation dynamics recorded in Greenland ice cores. Science, 282, 446-449.

Barnett, T. P., and R. Preisendorfer, 1987: Origins and levels of monthly and seasonal forecast skill for the United States surface air temperatures determined by canonical correlation analysis. Mon. Wea. Rev., 115, 1825-1850.
Beamish, R. J., C. E. Neville, and A. J. Cass, 1997: Production of Fraser River sockeye salmon (Oncorhynchus nerka) in relation to decadal-scale changes in the climate and the ocean. Can. J. Fish. Aquat. Sci., 54, 543-554.

Biondi, F., A. Gershunov, and D. R. Cayan, 2001: North Pacific decadal climate variability since 1661. J. Climate, 14, 5-10.

Blender, R., and M. Schubert, 2000: Cyclone tracking in different spatial and temporal resolutions. Mon. Wea. Rev., 128, 377384.

Bretherton, C. S., and D. S. Battisti, 2000: An interpretation of the results from atmospheric general circulation models forced by the time history of the observed sea surface temperature distribution. Geophys. Res. Lett., 27, 767-779.

Cassou, C., and L. Terray, 2001: Oceanic forcing of the wintertime low-frequency atmospheric variability in the North Atlantic European sector: A study with the ARPEGE model. J. Climate, 14, 4266-4291.

Casty, C., and Coauthors, 2005: Recurrent climate winter regimes in reconstructed and modeled $500 \mathrm{hPa}$ geopotential height fields over the North Atlantic/European sector 1659-1990. Climate Dyn., 24, doi:10.1007/s00382-004-0496-8.

Collins, M., S. F. B. Tett, and C. Cooper, 2001: The internal climate variability of HadCM3, a version of the Hadley Centre coupled model without flux adjustments. Climate Dyn., 17, 61-81.

Cook, E. R., R. D. D'Arrigo, and M. E. Mann, 2002: A wellverified, multiproxy reconstruction of the winter North Atlantic Oscillation index since A.D. 1400. J. Climate, 15, 17541764.

Feldstein, S. B., 2000: The timescale, power spectra, and climate noise properties of teleconnection patterns. J. Climate, 13, 4430-4440.

Fraedrich, K., 1994: An ENSO impact in Europe? A review. Tellus, 46, 541-552.

_ , and K. Müller, 1992: Climate anomalies in Europe associated with ENSO extremes. Int. J. Climatol., 12, 25-31.

Gillett, N. P., H. F. Graf, and T. J. Osborn, 2003: Climate change and the NAO. The North Atlantic Oscillation: Climate Significance and Environmental Impact, Geophys. Monogr., No. 134, Amer. Geophys. Union, 193-209.

Glueck, M. F., and C. W. Stockton, 2001: Reconstruction of the North Atlantic Oscillation, 1429-1983. Int. J. Climatol., 21, 1453-1465.

Grötzner, A., M. Latif, and T. P. Barnett, 1998: A decadal cycle in the North Atlantic Ocean as simulated by the ECHO coupled GCM. J. Climate, 11, 831-847.

Hartmann, D., J. M. Wallace, V. Limpasuvan, D. W. J. Thompson, and J. R. Holton, 2000: Can ozone depletion and global warming interact to produce rapid climate change? Proc. Natl. Acad. Sci. USA, 97, 1412-1417.

Hoerling, M. P., J. W. Hurrell, and T. Xu, 2001: Tropical origin for recent North Atlantic climate change. Science, 292, 90-92.

,,--- G. T. Bates, and A. Phillips, 2004: Twentieth century North Atlantic climate change. Part II: Understanding the effect of Indian Ocean warming. Climate Dyn., 23, doi:10.1007/s00382-004-0433-x.

Horel, J. D., and J. M. Wallace, 1981: Planetary-scale atmospheric phenomena associated with the Southern Oscillation. Mon. Wea. Rev., 106, 813-829.

Hoskins, B. J., and D. J. Karoly, 1981: The steady linear response of a spectral atmosphere to thermal orographic forcing. $J$. Atmos. Sci., 38, 1179-1196. 
Hurrell, J. W., 1995: Decadal trends in the North Atlantic oscillation: Regional temperature and precipitation. Science, 269, 676-679.

— ciated with the North Atlantic Oscillation. Climate Change, 36, 301-326.

— - Y. Kushnir, G. Ottersen, and M. Visbeck, 2003: The North Atlantic Oscillation: Climate Significance and Environmental Impact. Geophys. Monogr., No. 134, Amer. Geophys. Union, $279 \mathrm{pp}$.

—, M. P. Hoerling, A. Phillips, and T. Xu, 2004: Twentieth century North Atlantic climate change. Part I: Assessing determinism. Climate Dyn., 23, doi:10.1007/s00382-004-0432-y.

Kalnay, E., and Coauthors, 1996: The NCEP/NCAR 40-Year Reanalysis Project. Bull. Amer. Meteor. Soc., 77, 437-471.

Kiehl, J. T., J. J. Hack, G. B. Bonan, B. A. Boville, D. L. Williamson, and P. J. Rasch, 1998: The National Center for Atmospheric Research Community Climate Model: CCM3. J. Climate, 11, 1131-1149.

Kistler, R., and Coauthors, 2001: The NCEP-NCAR 50-year reanalysis: Monthly means CD-ROM and documentation. Bull. Amer. Meteor. Soc., 82, 247-267.

Klein, S. A., B. J. Soden, and N. C. Lau, 1999: Remote sea surface temperature variations during ENSO: Evidence for a tropical atmospheric bridge. J. Climate, 12, 917-932.

Kushnir, Y., W. A. Robinson, I. Blade, N. W. J. Hall, S. Peng, and R. Sutton, 2002: Atmospheric GCM response to extratropical SST anomalies: Synthesis and evaluation. J. Climate, 15, 2233-2256.

Latif, M., 1998: Dynamics of interdecadal variability in coupled ocean-atmosphere models. J. Climate, 11, 602-624.

— ity over the North Pacific and North America. Science, 266, 634-637.

Legutke, S., and R. Voss, 1999: The Hamburg atmosphere-ocean coupled circulation model ECHO-G. Tech. Rep. 18, Deutsches Klimarechenzentrum, Hamburg, Germany, 62 pp.

Luterbacher, J., and Coauthors, 2002a: Extending North Atlantic Oscillation reconstructions back to 1500. Atmos. Sci. Lett., 2, 114-124.

- and Coauthors, 2002b: Reconstruction of sea level pressure fields over the eastern North Atlantic and Europe back to 1500. Climate Dyn., 18, 545-561.

Mantua, N. J., S. R. Hare, Y. Zhang, J. M. Wallace, and R. C. Francis, 1997: A Pacific interdecadal climate oscillation with impacts on salmon production. Bull. Amer. Meteor. Soc., 78, 1069-1079.

Marshall, J., H. Johnson, and J. Goodman, 2001a: A study of the interaction of the North Atlantic Oscillation with ocean circulation. J. Climate, 14, 1399-1421.

- and Coauthors, 2001b: North Atlantic climate variability: Phenomena, impacts and mechanisms. Int. J. Climatol., 21, 1863-1898.

May, W., and L. Bengtsson, 1999: The signature of ENSO in the Northern Hemisphere midlatitude seasonal mean flow and high-frequency intraseasonal variability. Meteor. Atmos. Phys., 69, 81-100.

Meehl, G. A., and W. M. Washington, 1996: El Niño-like climate change in a model with increased atmospheric $\mathrm{CO}_{2}$ concentrations. Nature, 382, 56-60.

Merkel, U., and M. Latif, 2002: A high resolution AGCM study of the El Niño impact on the North Atlantic/European sector. Geophys. Res. Lett., 29, 1291, doi:10.1029/2001GL013726.
Moore, G. W. K., G. Holdsworth, and K. Alverson, 2002: Climate change in the North Pacific region over the past three centuries. Nature, 420, 401-403.

Osborn, T. J., 2004: Simulating the winter North Atlantic Oscillation: The roles of internal variability and greenhouse gas forcing. Climate Dyn., 22, doi:10.1007/s00382-004-0405-1.

Peng, S., and J. S. Whitaker, 1999: Mechanisms determining the atmospheric response to midlatitude SST anomalies. J. Climate, 12, 1393-1408.

Perlwitz, J., and H.-F. Graf, 2001: Troposphere-stratosphere dynamic coupling under strong and weak polar vortex conditions. Geophys. Res. Lett., 28, 271-274.

Pozo-Vázquez, D., M. J. Esteban-Parra, F. S. Rodrigo, and Y. Castro-Díez, 2001: A study of NAO variability and its possible non-linear influences on European surface temperature. Climate Dyn., 17, 701-715.

Raible, C. C., and R. Blender, 2004: Midlatitude cyclonic variability in GCM-simulations with different ocean representations. Climate Dyn., 21, 239-248.

- U. Luksch, K. Fraedrich, and R. Voss, 2001: North Atlantic decadal regimes in a coupled GCM simulation. Climate Dyn., 18, 321-330.

,-- , and $\longrightarrow, 2004$ : Precipitation and Northern Hemisphere regimes. Atmos. Sci. Lett., 5, 43-55.

Renold, M., U. Beyerle, C. C. Raible, R. Knutti, T. F. Stocker, and T. Craig, 2004: Installation of CCSM2.0.1 on a Linux PCcluster. Eos, Trans. Amer. Geophys. Union, 85, 290.

Rodwell, M. J., D. P. Rowell, and C. K. Folland, 1999: Oceanic forcing of the wintertime North Atlantic Oscillation and European climate. Nature, 398, 320-323.

Roeckner, E., K. Arpe, and L. Bengtsson, 1996: The atmospheric general circulation model ECHAM-4: Model description and simulation of present-day climate. Tech. Rep. 218, Max Planck Institute, Hamburg, Germany, 90 pp.

Rowntree, P. R., 1972: The influence of tropical East Pacific ocean temperatures on the atmosphere. Quart. J. Roy. Meteor. Soc., 98, 290-321.

Saravanan, R., 1998: Atmospheric low-frequency variability and its relationship to midlatitude SST variability: Studies using the NCAR Climate System Model. J. Climate, 11, 1386-1404.

Schneider, E. K., L. Bengtsson, and Z.-Z. Hu, 2003: Forcing of Northern Hemisphere climate trends. J. Atmos. Sci., 60, 1504-1521.

Shindell, D. T., R. L. Miller, G. Schmidt, and L. Pandolfo, 1999: Simulation of recent northern winter climate trends by greenhouse-gas forcing. Nature, 399, 452-455.

, G. A. Schmidt, R. L. Miller, and D. Rind, 2001: Northern Hemisphere winter climate response to greenhouse gas, ozone, solar, and volcanic forcing. J. Geophys. Res., 106, $7193-7210$.

,,--- , and M. E. Mann, 2003: Volcanic and solar forcing of climate change during the preindustrial era. J. Climate, 16, 4094-4107.

Sickmöller, M., R. Blender, and K. Fraedrich, 2000: Observed winter cyclone tracks in the Northern Hemisphere in reanalysed ECMWF data. Quart. J. Roy. Meteor. Soc., 126, 591-620.

Stephenson, 2003: The North Atlantic Oscillation in coupled climate models: A CMIP1 evaluation. Climate Dyn., 20, 381399.

Thompson, D. W. J., J. M. Wallace, and G. Hegerl, 2000: Annular modes in the extratropical circulation Part II: Trends. J. Climate, 13, 1018-1036. 
Timmermann, A., M. Latif, R. Voss, and A. Grötzner, 1998: Northern Hemispheric interdecadal variability: A coupled air-sea mode. J. Climate, 11, 1906-1931.

Trenberth, K. E., and J. W. Hurrell, 1994: Decadal atmosphereocean variations in the Pacific climate dynamics. Climate Dyn., 9, 303-319.

Visbeck, M., H. Cullen, G. Krahmann, and N. Naik, 1998: An ocean model's response to North Atlantic Oscillation-like wind forcing. Geophys. Res. Lett., 25, 4521-4524.

von Storch, H., and F. W. Zwiers, 1999: Statistical Analysis in Climate Research. Cambridge University Press, 510 pp.

Wallace, J. M., and D. S. Gutzler, 1981: Teleconnections in the geopotential height field during the Northern Hemisphere winter. Mon. Wea. Rev., 109, 782-812.

Walter, K., and H. Graf, 2002: On the stability of regional connection between North Atlantic Oscillation and sea surface temperature. J. Geophys. Res., 107, 4338, doi:10.1029/ 2001JD000850.

__, U. Luksch, and K. Fraedrich, 2001: A response climatology to idealized midlatitude thermal forcing experiments with and without a storm track. J. Climate, 14, 467-484.

Wanner, H., S. Brönnimann, C. Casty, D. Gyalistras, J. Luterbacher, C. Schmutz, D. B. Stephenson, and E. Xoplaki, 2001: North Atlantic Oscillation-Concepts and studies. Surv. Geophys., 22, 321-382.

Weisheimer, A., D. Handorf, and K. Dethloff, 2001: On the structure and variability of atmospheric circulation regimes in coupled climate models. Atmos. Sci. Lett., 2, 72-80.

Wolff, J. O., E. Maier-Reimer, and S. Legutke, 1997: The Hamburg ocean primitive equation model HOPE. Tech. Rep. 13, Deutsches Klimarechenzentrum, Hamburg, Germany, 98 pp.

Wu, P. L., and C. Gordon, 2002: Oceanic influence on North Atlantic climate variability. J. Climate, 15, 1911-1925.

Wunsch, C., 1999: The interpretation of short climate records, with comments on the North Atlantic and Southern Oscillations. Bull. Amer. Meteor. Soc., 80, 245-255.

Zhang, Y., J. M. Wallace, and N. Iwesaka, 1992: Is climate variability over the North Pacific a linear response to ENSO? $J$. Climate, 5, 1468-1478. 